\title{
EXPLORING THE ROLE OF DANCE IN ARCHITECTURAL EDUCATION
}

\author{
C. Daskalakos
}

Department of Architecture

University of the Witwatersrand

Johannesburg, South Africa

e-mail: Christos.Daskalakos@wits.ac.za

\section{ABSTRACT}

The "dance_space" project is an exploratory workshop with the objective to facilitate improved spatial design outcomes in first year architectural design students. In architecture, certain abstract spatial concepts are difficult to teach through the medium of language, which is less accessible to underprepared students and to sensory learners. The area of research is on using alternative pedagogies in spatial learning, looking at movement practice as a perceptual tool that can contribute to the development of spatial intelligence in architectural students with the objective to facilitate improved spatial design outcomes.

Keywords: word, architectural education, dance, spatial intelligence, spatial design

Dance in architectural education has the potential to broaden students understanding of design by developing a key design skill, spatial awareness. While this may develop through the course of design projects, there are two factors that could inhibit this. The first is that the relationship and understanding of space differs from person to person and is influenced by cultural background, social circumstances and personal experience. In architecture, certain abstract spatial concepts are difficult to teach through the medium of language due to lexical semantics (Montello 1995). This is particularly relevant in the South African context where differences in home language and a lack of preparedness of the students by the education system have an impact on the success of student understanding (Janse van Rensburg 2015).

The second factor influencing the development of spatial awareness is the challenge of architectural education to incorporate influences from many disciplines. The technological basis of building which not only includes structure but other aspects such as energy efficiency, require an understanding of basic physics. This and the way architects represent building through two or three dimensional drawings can sometimes lead to the building being treated as an object ignoring the experiential aspect of space (Spurr 2007; Vroman et al. 2012). Teaching an experiential awareness of space is challenging as students are not a homogenous group. Cultural and social factors influence their personal experiences.

Our understanding of space in architecture can be seen in two ways. The first is objective 
and is expressed through legislation like the National Building Regulations, which quantify minimum building standards, and through the science of ergonomics. While this can be a rational understanding of space and lead to a level of competent building design, there is a second, deeper understanding of space which deals with more subjective relationships and aspects of space. This is often difficult to define and rationalise as we learn about this aspect of space heuristically. One of the ways in which it is possible to transcend from an objective to the subjective experience of building is to look to other disciplines such as dance (Spurr 2007; Bronet and Schumacher 1998).

The challenge of architectural education is to develop spatial awareness that includes both these objective and subjective aspects. As this cannot rely on a traditional linear pedagogy, other ways should be explored. One of these is to include haptic experience of space through non-verbal methodologies. In the dance_space workshop project carried out with first year architectural students at the University of the Witwatersrand, the use of dance and music were used as a way for students to explore and expand their understanding of space.

The relationship between dance and architecture has a long tradition in architectural education. Walter Gropius, founder and director of the Bauhaus (1919-1932), writes that one of the intentions of the institution was to bring together all the visual arts, including both architecture and stage work. Oskar Schlemmer, head of the sculpture studio, went on to create the Bauhaus stage shop, where he used choreography to explore the relationship between space and movement. The question of how creative work and experience can also give rise to knowledge was also one of his concerns. In his choreographies, he explored two ways in which a dance can relate to space. Firstly, he proposes the concept of "cubical space", which he sees as determined by the geometry of space in relation to human biology. Movement of the dancer in such a space, he contends, is determined mechanically and rationally. On the other hand, he proposes a relationship to space which is based on what he calls the "invisible functions of (the) inner self". "Movement through this space is determined organically and emotionally" (Schlemmer, Moholy-Nagy and Molnár 1979).

We see these themes of creating knowledge through experience, and the relationship of space from a rational or emotional perspective, being picked up and explored later by both design lecturers and choreographers (Brown 2003; Ersoy 2011; Gavrilou 2003; Moeller 2006; Schlemmer, Moholy-Nagy, and Molnár 1979; Spurr 2007). The relationship between dance and architecture is based on various views of the shared elements of body and space, and between ways of thinking, which George Lakoff describes as being "directly grounded in perception, body movement, and experience of physical or social nature" (Lakoff 1987). 


\section{ARCHITECTURAL EDUCATION}

In order to prepare the South African architect the architectural pedagogue needs to prepare the student with a diverse set of skills (Janse van Rensburg 2015).

Within this context there is also a diverse relationship to space based on perspectives formed by gender, culture, etc. Roger Copeland (1983) proposes that in a postmodern world our relationship to space is relative and based on our individual experience. It is a dynamic interaction which is a reflection of postmodern architecture that has shifted from an approach of the creation of buildings that have universal application to ones that are determined by their context and use (Copeland 1983). He compares this to dance, which like architecture has distinct modern and postmodern identities. His motivation for making this comparison is that one of the characteristics of postmodern architecture is the inclusion of the body with an emphasis on the relationship between body and building. Yudell, quoted by Copeland (1983), suggests that one of the ways in which we can re-establish our relationship to architectural space is by looking at dancers who he says have an emotional relationship to space. Dance then could be a way to bring into awareness our individual relationship to space.

In contrast to a reductionist approach to education, where one system fits all, our relationship to knowledge and skills has to be a personal one (Neumeier 2013). In a complex and diverse society such as South Africa, this is especially important - as the trained professional should have the knowledge and skills that would allow rapid change and skills to be portable and transferable. In this way we can develop an ability to be innovative to meet new challenges. This is something that cannot necessarily be taught in a traditional way and also includes an element of personal development.

Based on Howard Gardner's (1993) theory of multiple intelligences, Leon Van Schaik (2008) identifies "spatial intelligence" as being a meta-skill particularly important to architects. A meta-skill is a higher order of skill that enables other skills to occur (Mindell 2001). Spatial intelligence, in this context, is our ability to navigate and recognise space and objects in space. Given the cultural and social diversity of students studying architecture, the question arises as to how one teaches such abstract spatial concepts that are difficult to convey through the medium of language. As mentioned above, language creates particular semantic difficulties, which could lead to misunderstanding and possibly alienation of the student.

Despite the cultural and personal differences in our cognition of space, Daniel Montello (1995) gives two aspects that create a common universal spatial experience. These are based on the nature of our common nervous system evolved over time to navigate space, and the fact that we share the same body structure. Movement through space, such as dance, could be a way to cross the cultural divide and find a common spatial experience. The body and movement 
become a common reference point.

\section{ARCHITECTURE DANCE COLLABORATIONS}

An example of the exploration between dance and architecture is a project led by Evelyn Gavrilou, of the National Technical University of Athens, to explore choreographic principles of movement and how these could be used to enrich the design of space (Gavrilou 2003). Students looked at two contrasting approaches to choreography and dance was used as a way to bring about a greater awareness of the body and how this could affect the design of a spatial experience. The two choreographers investigated were George Balanchine and Merce Cunningham. Balanchine's choreography is structured around setting up moments in space linked by movement while Cunningham's choreography is focused on process and the use of body parts to explore a range of possibilities through improvisation.

Zehra Ersoy (2001), on the other hand, collaborated with a choreographer to explore how space and architecture could be embodied by the students, and so creating greater awareness of space through personal experience. The intention was that, through the dance exercises, the students' understanding of space would be transformed. According to Ersoy, approaches to design focus on the user and their experience in space and that somewhere architectural pedagogy needs to provide the opportunity for students to understand this relationship through an embodied experience.

Two further examples explore the relationship between body and space from two perspectives. The first is the effect that space through architecture can have on movement and the second being the affect movement can have on the creation of space itself.

Choreographer Carol Brown (2003) ran a workshop at the Isadora and Raymond Duncan Centre for Dance exploring the external spaces of the centre through movement, finding the relationships between the body and the built structures. Brown used touch to create an awareness of the built environment in relation to the body's own kinesphere, a term defined by Rudolf Laban as "the sphere around the body whose periphery can be reached by easily extended limbs without stepping away from that place which is the point of support when standing on one foot" (Laban 1966, 10).

The exploration of movement shaping space was explored by choreographer Martin Moeller (2006) through a number of performance pieces. These were designed to take place in a theatre and explore the elements and movement that shape space. His performance pieces "Spillout" and "Beating a Path" use a flexible backdrop as the architecture with which the dancers interact and shape.

Both these choreographers are using dance and architecture to demonstrate the strong 
relationship that movement within space has to our spatial experience. Using dance as a pedagogic tool would allow for this exploration by students, bringing them to a greater awareness of their bodies, their emotional response to space and the underlying concepts they have about space.

\section{dance_space WORKSHOP}

In order to explore an alternative pedagogy that would promote spatial awareness in first year architecture students, a creative movement workshop called "dance_space workshop" was planned for the first week of the new academic year. The workshop was part of the design course curriculum and included all the student's registered for this course. This was made up of 81 students with an almost equal distribution of male to female $(m=40, f-41)$; and with a racial distribution of 29 black students, 20 Asian students and 32 white students.

Creative movement is seen as a dance process based on improvisation and not formal dance movements. This allows for a process of discovering something new through free association that may not have been anticipated (Blom and Chaplin 1988). Anne Hurst (2010) points out that this leads to creating new relationships to self, others and the environment.

The workshop is based on two premises. On the one hand, our experience of space is both personal and socially constructed. In this context, we cannot think of space as universal but rather that we inhabit many different spaces which intersect each other, much as there is no one dance or one architecture (Lopez y Royo 2006). The workshop intends to allow students to explore their individual relationship to space through a kinaesthetic experience which Helle Brabrand (2005) sees as a powerful factor in generating space. On the other hand, there is an aspect of space that is universal and an architectural designer should be able to transcend the personal in order to create the spaces demanded by the client. For this aspect dance/movement creates awareness of the body and through this an immediate spatial experience (Foster 1986; Pickering 2009). This awareness has both a physical and a cognitive component. Emotions also play a role in the dance. Our emotional experience to dance can be created using music (Christensen et al. 2014). An embodied learning experience, such as the workshop, could lead to an understanding of space, by integrating both the physical and cognitive - body and mind (Ersoy 2011).

The questions that the workshop seeks to explore are: how can dance contribute to architectural education, and specifically, can creative movement practice contributes to the development of spatial intelligence in architectural students? 


\section{DESIGN OF THE PROJECT}

The design of the research project is based on action research, a reflective research methodology that allows for inquiry and discussion as part of the research. The aim is to create knowledge rather than solve problems, and as such, it has often been used in educational environments in order to develop more effective pedagogies (Ferrance 2000). Action research includes the idea that knowledge is socially constructed through human interaction based on the values of both researcher and participants allowing for a collaborative creation of knowledge (Brydon-Miller, Greenwood and Maguire 2003). This methodology reflects the workshop design where the researcher is not a separate observer dispensing information but actively involved in the creative process. It includes both researcher and subjects in a participatory process and therefore there is an element of subjectivity by both the researcher and the subjects. An aspect of action research is reflexivity, a process through which to the researcher positions themselves and makes explicit any assumptions, biases, and gives reasons for any interpretations (Huang 2010). The author has trained in formal dance techniques as well as a therapeutic dance modality known as Biodanza. Although actively involved in the workshop the author relies on the voices of the participants to reach a conclusion. The participants reflected on their experience of the workshop through the verbal debriefing, reflective writing and questionnaires as described below. The author also conducted an open ended interview with the design course lecturer. This form of research provides an opportunity for all involved to continue individually or collectively with the process of inquiry (Reason and Bradbury 2008).

This does not rely on any single method for collecting and analysing data and various qualitative research methods form part of the methodology and can include oral and written reports of the participants, recordings via photographs and video, questionnaire or survey, and structured interviews (O’Brien 1998; Ferrance 2000).

What distinguishes action research from conventional research is that it is carried out in real-world situations and involves the affected people in the process. The project was initiated with an explanatory lecture, which outlined the parameters of the workshop. In order to maintain spontaneity, the communication of the details of the workshop was not given up front but rather in stages. However, at each stage, the participants had the choice to continue or withdraw. As the workshop progressed from the drawing of figures to the movement component it became evident that some participants withdrew at times to the sides of the studio. They were not forced to participate. In the final feedback session it emerged that some of the students were uneasy with what they perceived as the chaotic nature of the workshop, while others made comments in respect to the music used which they found they did not relate to. With regard to the data collected, the participants were given a full explanation of the project 
and process and then asked to sign a letter of consent in which assurance was given that the data would be secured and that confidentiality would be maintained by the researcher in that the written feedback would not be linked to any names. In this regard the project did not have any formal assessment and did not include an allocation of marks. Students did give permission for the workshop to be recorded both via video and still photography with the understanding that these images would be used in presentation.

The workshop was divided into two parts; both included an experiential process followed by reflective writing. The creative movement took place in the second part.

\section{Part 1 - First day of the new academic year}

On the first day of the new academic year, the design course co-ordinator, Kirsten Doermann presented a lecture on ergonomics. The students were then given the task of setting up the furniture in their design studio based on practical and technical considerations. The layout was to be arranged to facilitate a working environment that promoted group interaction. At the end of this session the students were asked to write about their experience by answering the following questions.

- How did you and your group arrange the space (process)

- Why you and your group arranged the space this way (reasons)

- $\quad$ Name at least three criteria that influenced your decision (reflection)

\section{Part 2 - Fourth day of the new academic year}

On this day, the author presented a lecture to the students on the relationship between space and movement followed by the dance_space workshop which consisted of three stages. To create spontaneity, the students were briefed just before each stage. The three stages of the dance_space workshop were:

a) Stage 1: Creating the cardboard cutouts: Working in pairs, each student took turns to lie on a large piece of corrugated cardboard $(1 \mathrm{~m} \times 2 \mathrm{~m})$ and were encouraged to create interesting body shapes (Figure 1). The purpose of the cut-outs was to create a body centred experience.

b) Stage 2: The students were asked to set up the cardboard shapes, both negative and positive, into a sequence anywhere in the design studio. The sequence was to be connected with a coloured ribbon (Figure 2). It did not matter if the sequences overlapped as the 
students were free to set up anywhere in the studio and were also encouraged to move the furniture, if they wanted to, and use it as part of their installation.

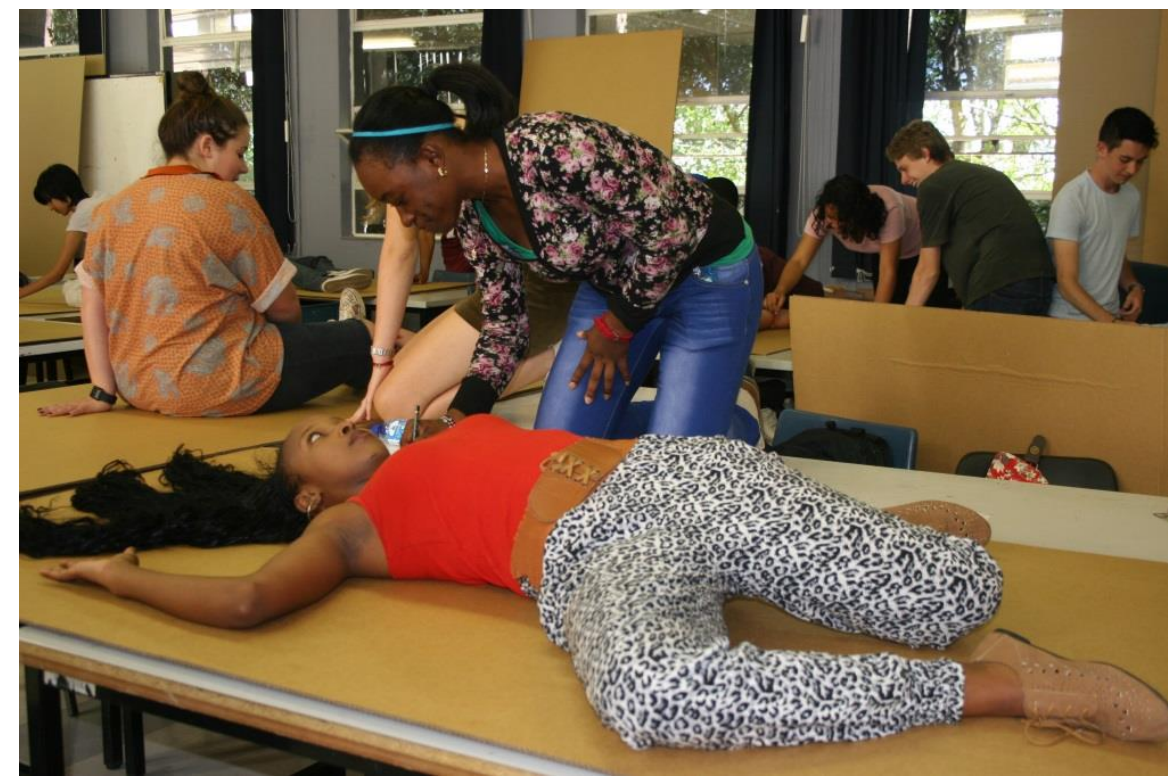

Figure 1: Body shape being outlined on card (Photograph: Sally Gaule)

c) Stage 3: This consisted of the creative movement aspect. Three pieces of music were played. The first piece was rhythmic and upbeat and each group was encouraged to move creatively along the sequence they had set up, using the ribbon as the guide. Once each group had performed this movement sequence, a second piece of music was played, this time a classical work. Each group was given the opportunity to move along their sequence for a second time. Once this was completed, and to wrap up the experience, a further popular piece of music was played, and students were free to move through all the installations.

\section{THE DATA}

The project is exploratory research into the role of dance in architectural education, using qualitative data to identify emerging themes that could inform the research. Data was collected in five ways in order to create data triangulation and facilitate a deeper understanding (Denzin 1970).

Direct Observation and Recording: The student's experiential activities were observed by the facilitator and recorded by the students through sketches and diagrams in Part 1, while Part 2 was recorded through stills photography and video recordings.

Reflective Writing: There were two exercises which took place after the experiential 
components. Students were given the opportunity to do this at home and so enough time was given for reflection. The reflective writing exercises included diagrams and drawing in most cases.

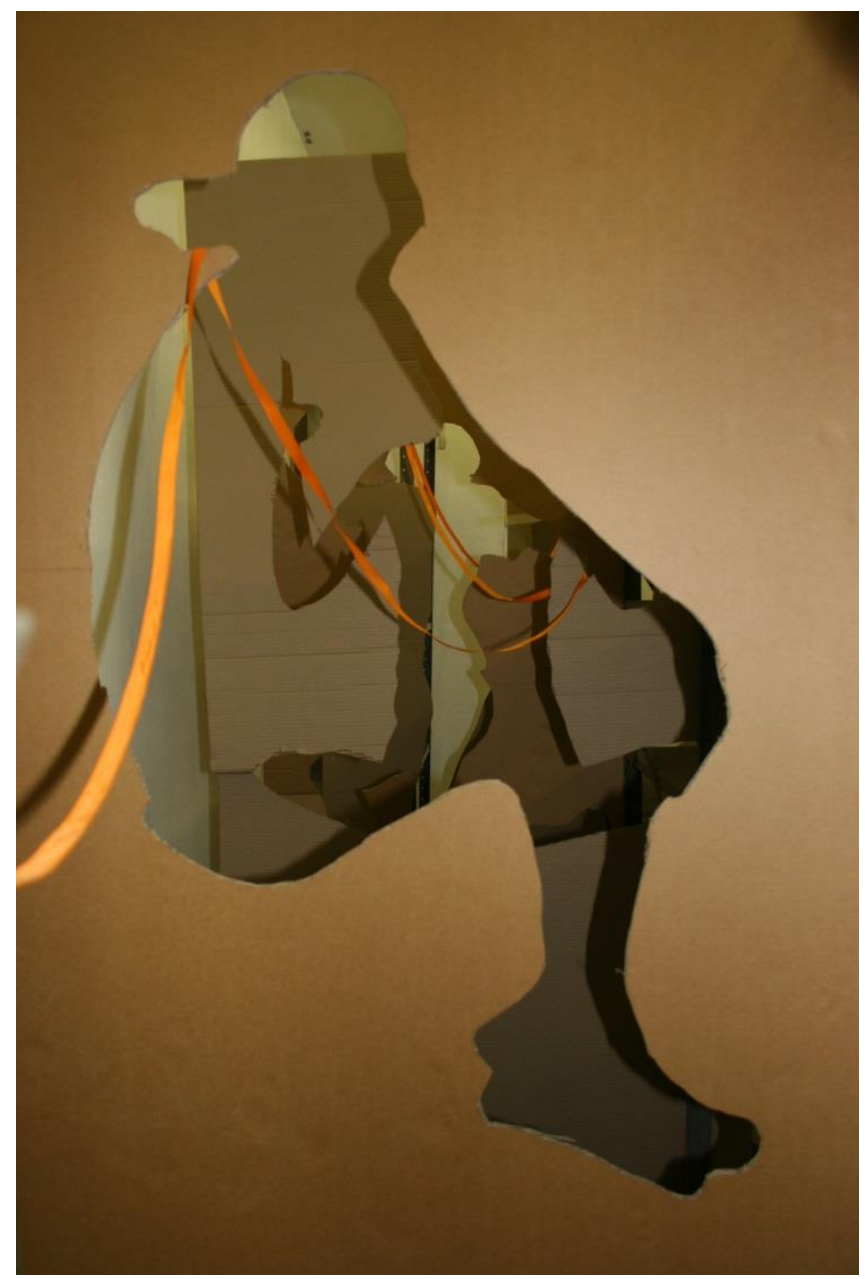

Figure 2: Assorted body shapes connected with ribbon (Photograph: Sally Gaule)

Verbal Debriefing: The creative movement experience (Part 2) was followed immediately by a verbal debriefing using a methodology called Deep Democracy, the Lewis Method (Lewis 2000) facilitated by the author. This session was also recorded via video for future reference.

Interview: An interview was conducted with the design course co-ordinator, Kirsten Doermann, ten months after the project, to give her impressions of the creative movement workshop and to comment on whether she experienced any difference in the way students engaged with the spatial components of their studio projects.

Feedback survey: Students were asked to fill in a feedback survey 10 months after the project which contained three questions: 
- Do you think that the workshop had any effect on your design work this year?

- Do you think that the workshop changed your perception of space?

- Do you think that the workshop is useful for architectural student?

\section{ANALYSIS}

A comparison between the two experiential components demonstrated two different approaches to the spatial configurations. Part 1 reflects the practical requirements while the prime generator in Part 2 were experiential, emotional and narrative. Both these approaches are described by the students in their reflective writing as discussed below.

The reflective writing in Part 1 tended to be based on practical considerations of setting up the furniture. While there was some element of spatial exploration, these were generally descriptions of the various configuration patterns of the furniture. Overall the criteria used to set out the space were based on functional aspects with only one reference to the selected layout facilitating interpersonal relationship and communication of the group.

In looking at the reflective writing in Part 2, the author elected to ignore any comments that referenced the lecture given that day regarding the relationship of movement and space. This would just be a regurgitation of the lecture content. In order to focus on themes relating to spatial aspects, all comments giving a description of the process and instructions were also ignored. An analysis of the remaining comments identified a number of themes as follows.

"I, at first did not understand the assignment until I experienced it for myself." - Participant.

\section{Chaos vs Order}

Comments were made about the chaotic nature of the dance_space workshop (Figure 3). Some students were uneasy about the fact that they did not receive the full instructions up front and so felt they did not know where they were headed. The various installations were perceived as "chaotic and messy" due to lack of planning and communication between the group members leading to what was perceived as a disorganised end product. However, other students saw the chaos as a creative learning opportunity to the extent that one group deliberately set out to create a sense of chaos identifying their zigzag arrangement as giving people a sense of urgency and chaos. This so called organised chaos was identified as also being part of the process where some decisions regarding the layout were conscious choices while others seemed arbitrary creating "an air of anarchy and diversity". Some felt that by immersing into this organised yet chaotic environment an opportunity for learning was created. 


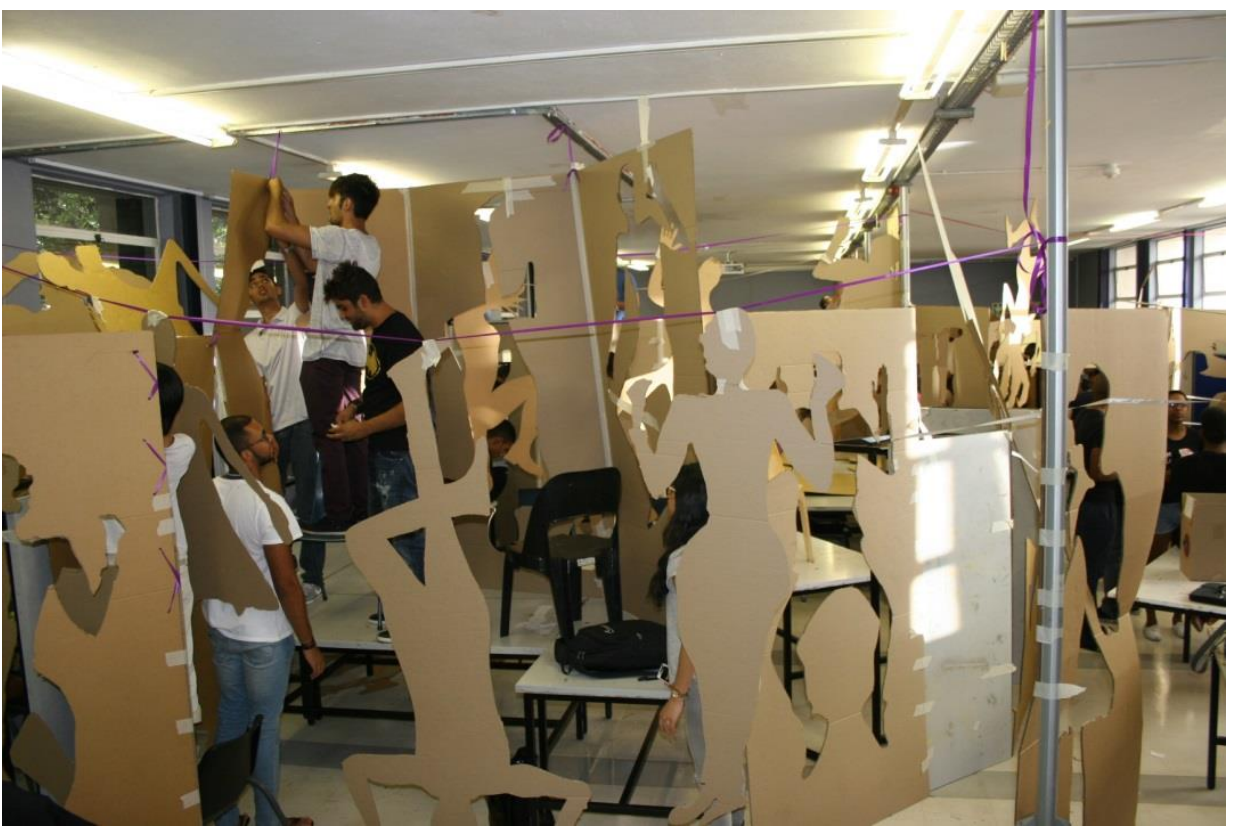

Figure 3: Some students experienced the space as chaotic (Photograph: Sally Gaule)

\section{Space as narrative}

Two groups consciously chose to arrange their sequence as a narrative of their anticipated journey as architectural students. One group identified the struggle that this process represented and chose to create their sequence in two parts; the first a difficult space to negotiate and then an open and freer space representing the joy of achieving their objectives. The second group created a structure representing a building which symbolised the same path (Figure 4). In their own way the students identified the possibility that movement through a space can also tell a story. In other instances the shapes were also seen as being able to relate a story. For example, an octagonal structure was seen as representing the students as individuals able to support each other in achieving their objectives.

\section{Emotional aspects of space}

A number of students mentioned the emotional aspect of space. This could have been prompted by the author's reference to the music as an emotional component of the workshop. However, the comments did present a variety of views. There was a definite recognition that the designer is able to manipulate and even control how someone felt and experienced time through the manipulation of space. Space could affect human moods and emotions by manipulating the body and inducing a reaction to certain types of spaces. An example given was the difference between wider space, which would allow people to feel more free and relaxed, and the narrow space, which would make them feel congested and overwhelmed. One group deliberately 


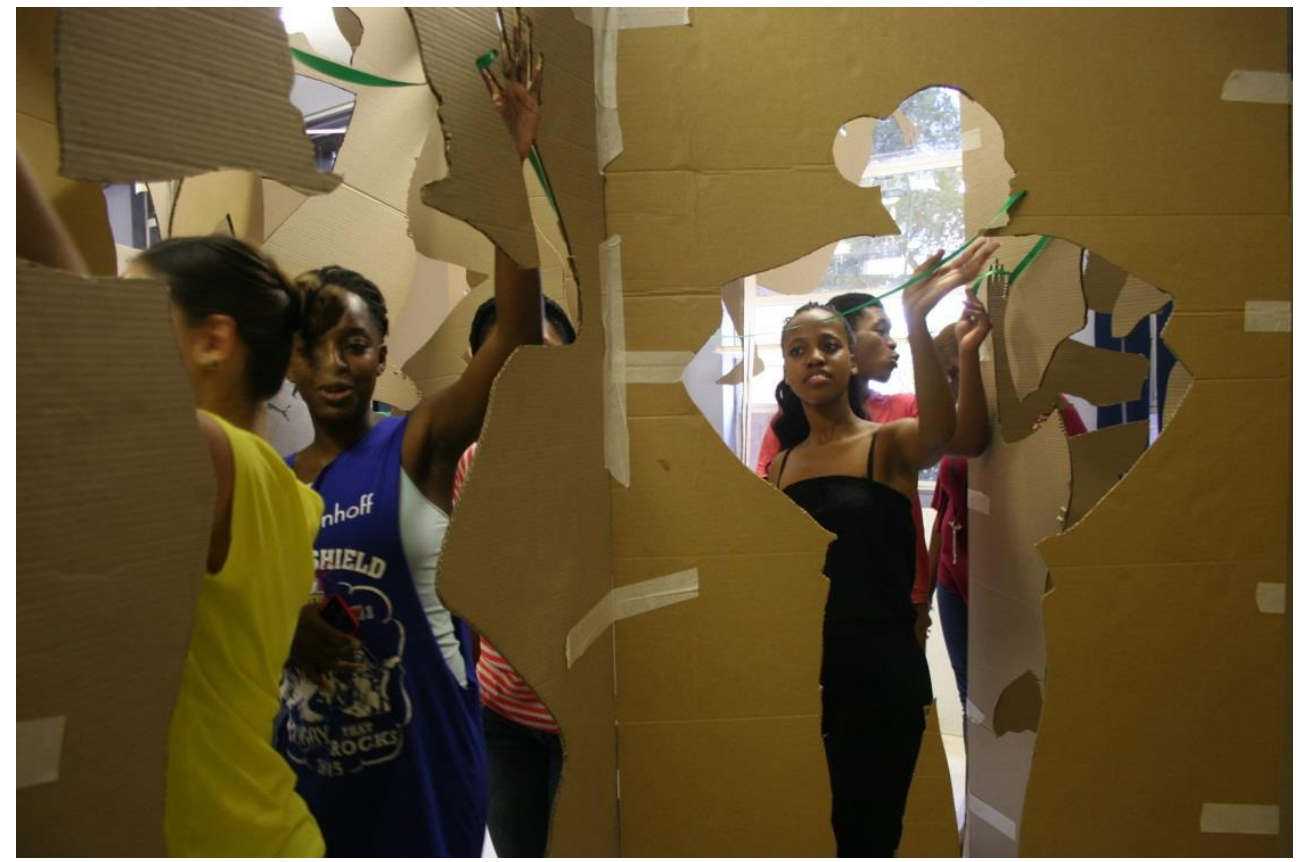

Figure 4: Space articulated as narrative (Photograph: Sally Gaule)

arranged their sequence in a way which could avoid feelings of claustrophobia. Their view was that incorrect use of space could lead a person to be uncomfortable, especially when their movement was restricted. Space was seen as being able to determine levels of comfort. A different emotion was the intention of another group when they used the figures and the postures they depicted in ways that were intended to create some humour (Figure 5). This group clearly stated that to evoke this emotion was what influenced their decisions. Other groups also identified the fact that people interacting with the cut-out figures could create feeling and emotion. The negative cutouts for one student appeared to reflect the "low notes of life" and were seen as depressive. Generally, among the students who included a comment based on emotion, there was a recognition that dancing or moving through the space could elicit different emotions. These could be a result of the music, which evoked emotions and "took the experience to another level". Although there was also an awareness that everyone has a personal connection to space and the object in it, which would elicit different emotions such as the element of surprise or discovering hidden beauty. One group, using emotion as a design generator, set out to create spontaneity, adventure and mystery. An intention was also set up by another group to create a connection to the space instead of allowing people to walk through mechanically. An emotion that was also considered outside of the personal was respect for other groups and to create the sequences in such a way as not to intrude on the space of the other. 


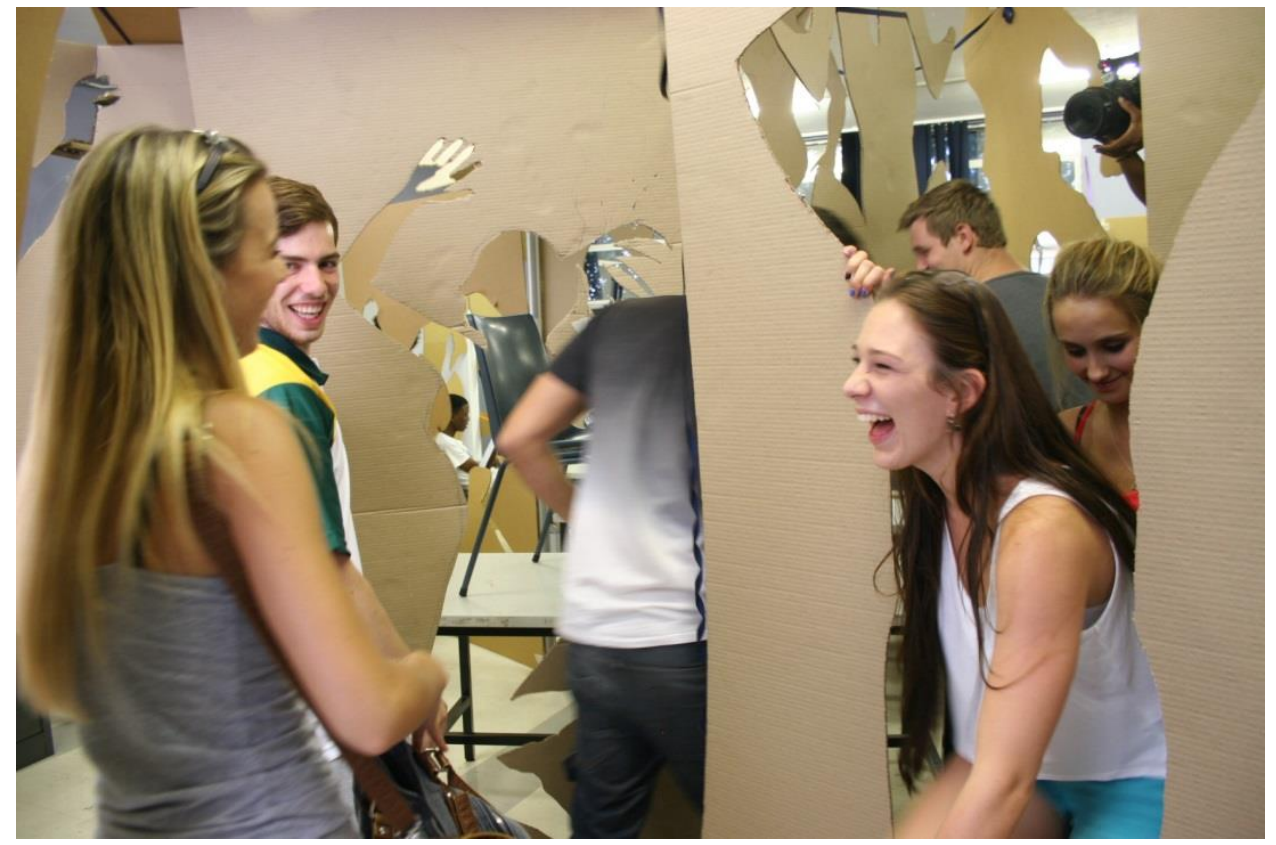

Figure 5: Humour as one of the emotional aspects of space being portrayed (Photograph: Sally Gaule)

\section{Space Influencing perception and experience}

Perceptions of space and experience could also be influenced in a number of ways. Firstly, the way one chooses to navigate the space would influence their experience. This could be deliberate by forcing a point of entry and direction of movement. It could also be composed to create a sense of order. Space could be manipulated so as to create contrasting positions, thus stimulating people's minds and activate their interest. This creates a relationship between people and the environment, leading to interaction with the space (Figure 6). This allows people to contemplate the meaning of the space, which could be revealed by the way it is structured. For example, a chaotic space would force people into contorting themselves, making the space change in character with each movement. Architecture and its distinct features are experienced through movement. Thus dance allows a person to evaluate the spatial arrangements and identify more efficient arrangements. Other elements that students included in their design considerations were the effect of light on the sequence and the pace with which movement took place, affecting the level of detail experienced. Architectural elements were identified as determining the spatial experience. For example vertical wall planes were seen as instrumental in defining space and providing a sense of enclosure. By manipulating the architecture it could also be possible to force people to see things from different perspectives, which then recognise "that people have different opinions". 


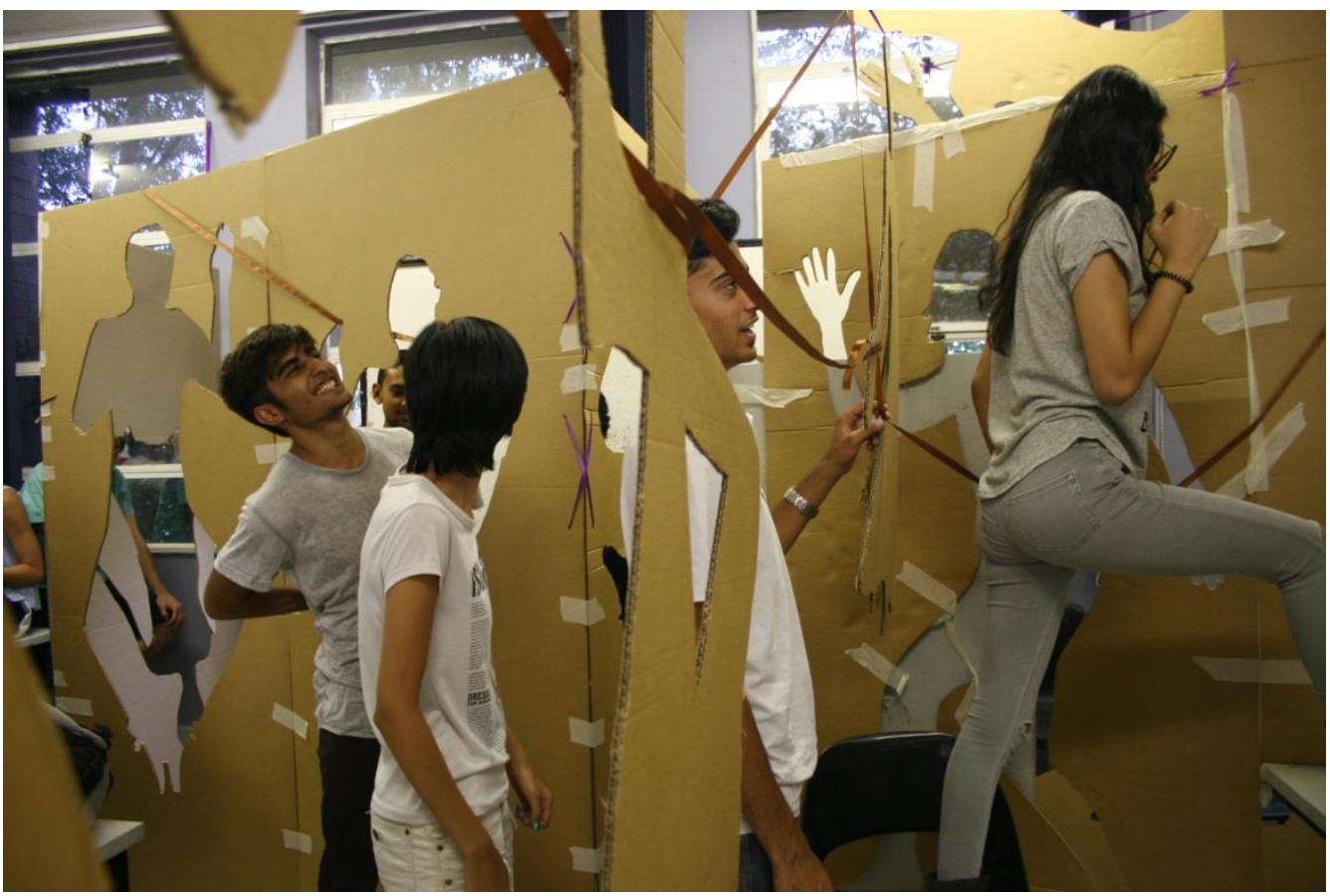

Figure 6: The different arrangements compel students to interact in different ways to the space (Photograph: Sally Gaule)

\section{Manipulation of body and behaviour}

Participants saw the value of using the body as a way of learning. The way the body moves and functions could be used to design the spaces and at the same time the objects placed in the space could influence the way the body moves and how the space is "felt" (Figures 7, 8). Flow was mentioned in a number of comments, both positively and negatively. By inhibiting movement and flow it is possible to create an emotion related to the difficulty of movement. Some installations purposely created spaces that forced the participants to twist and turn in different directions. This distortion of the body was seen as a way of creating different experiences by forcing participants to interact with the installation. Creating awkward movement and sequences also allowed unusual relationships to the surrounding. Both shape and the music were seen as factors that determined the tempo of movement. Wide spaces took less time to negotiate while narrower spaces took more force. While the project focused on space it also elicited insight on posture and the body. One of the comments was, “... I realise that some people are much bigger than me - cannot design space only from my body perspective."

During the verbal debriefing, similar themes to those in the reflective writing were identified. This component took place before the reflective writing and so the comments were not extensively articulated. 


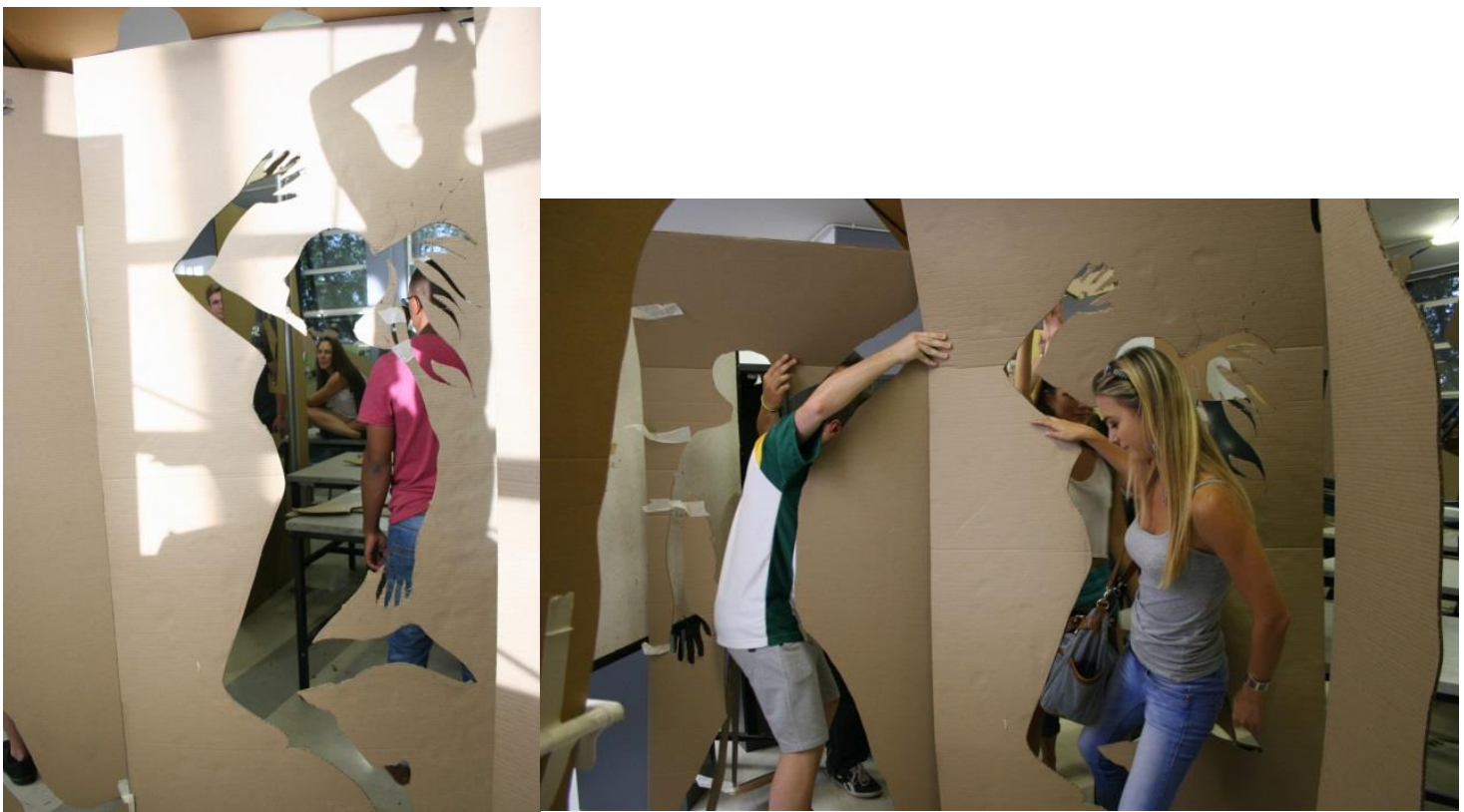

Figure 7 and 8: The objects and space manipulate the body movements (Photograph: Sally Gaule)

\section{CONCLUSION}

Action research provides a view of given reality rather than setting up general solutions, raising more questions that it does conclusion (Evered and Susman 1978; Da Ponte 2008). It is this context the following conclusions are offered.

The responses in the feedback form showed a disconnection between the project and later design work. While 82 per cent of the responses on the form agreed that the project had changed their perception of space, only 54 per cent could see that this had affected their later design work. This highlights two issues that emerge from this project. The first is that the students have no alternative experience to compare against. They were all in their first year of study and in the first week of the academic year. Having said that, the reflective writing shows a deep level of engagement with space and a conceptual grasp that is quite sophisticated. To address this issue it may be better to conduct such a workshop with students in higher years of study that would have something to measure their experience against. The second is that the workshop was conducted as a stand-alone project with no structured connection to later projects. However, the feedback of the design course lecturer Kirsten Doermann, who set the project following on from the workshop, is that the students in that year performed better on that project compared to previous years. It is clear that a project such as this would have greater value if incorporated into a design project where students are able to incorporate their insights and lessons from the experiential process directly into a design project was been the case with both Ersoy (2011) and Gavrilou (2003).

A comparison between the observation and data of the two experiential components of the 
dance_space workshop demonstrated two different approaches to the spatial configurations. The first approach, as demonstrated in Part 1 of the workshop, appears rational and the criteria used to design the layout of space are based on practical requirements of the various groups. On the other hand, the sequences set up by the students in Part 2, were free of such considerations and the prime generators were experiential, emotional and narrative. As the relationship to space is determined both rationally and emotionally it would be useful to include both aspects and not view them as opposing pedagogies. Approaching the exploration of space from an emotional, non-verbal perspective offers an opportunity to transcend the limitations of culture and language, which usually are represented by more cognitive processes and explore the more commonly held experiences. The embodied experience of creative movement offers such an opportunity, which by its very nature transcends the limitations mentioned above but also can have a very powerful connection to emotion. The reflective writing exercise and debriefing session are opportunities to integrate the emotional experience into a more cognitive understanding.

The challenges presented in this project were the size of the studio, number of students and the sound equipment. In terms of the space available, there was overcrowding not allowing the participants ample space within which to create their installations, leading to confusion. In a workshop of this nature it is difficult to work effectively with a large group, especially when the overcrowded space did not allow for easy visual connection and direction from the facilitator. Lastly, the sound system was not strong enough to deliver the music across the whole studio and so it was difficult for participants to relate to the music. Despite these challenges the participants' reflective writing demonstrated that they did engage and received value from the project. If this workshop were to be repeated, it would have to be managed in terms of numbers and space available, giving the opportunity for creative movement to be easier to facilitate. It would appear that although the workshop as a stand-alone does have some merit, however it could be more effective if it were to be incorporated into a longer project that included creative movement, design and reflection.

The process of inquiry in action research is as important as the outcomes and knowledge it generates. Implied in this, is that there is learning to be gained in the process which involves a reflective component. This is only possible over time and the workshop cannot therefore be judged as a stand-alone piece of work. The efficacy of this line of research depends on repetition and reflection over a period of time and it would be important to see this workshop as the first step in a research project that will find its own natural conclusion. Given the challenges and lessons learnt from this workshop, it clearly has scope for future development and warrants repetition and elaboration. 


\section{REFERENCES}

Blom, Lynne Anne and Tarin L. Chaplin. 1988. The moment of movement: Dance improvisation. Pittsburgh: University of Pittsburgh Press.

Brabrand, Helle. 2005. Architecture and embodyment. Nordisk Arkitectur Forskning 3: 55-67.

Bradbury Huang, Hilary. 2010. What is good action research? Action Research 8(1): 93-109. https://doi.org/10.1177/1476750310362435

Bronet, Frances and John A. Schumacher. 1998. Design in movement: The prospects of interdisciplinary design. https://www.researchgate.net/publication/249484114_Design_in_Movement_The_ Prospects_of_Interdisciplinary_Design

Brown, Carol. 2003. Dance-architecture Workshop. Isadora and Raymond Duncan Centre for Dance, 29 September to 5 October 2002. Carol Brown Dances and Collaborations. 2003. http://www.carolbrowndances.com/writings_pubs.php

Brydon-Miller, Mary, Davydd Greenwood and Patricia Maguire. 2003. Why action research? Action Research 1(1): 9-28.

Christensen, Julia F., Sebastian B. Gaigg, Antoni Gomila, Peter Oke and Beatriz Calvo-Merino. 2014. Enhancing emotional experiences to dance through music: The role of valence and arousal in the cross-modal bias. Frontiers of Human Neuroscience 8: 1-9. https://doi.org/ 10.3389/fnhum.2014.00757

Copeland, Roger. 1983. Postmodern dance postmodern architecture postmodernism. Peforming Arts Journal 7(1): 27-43. https://doi.org/10.2307/3245292

Da Ponte, João Pedro. 2008. Researching your own practice. In Handbook of mathematics teaching research, ed. B. Czarnocha, 19-35. Rzeszów: University of Rzeszów.

Denzin, N. K. 1970. The research act in sociology. Chicago: Aldine.

Ersoy, Zehra. 2011. Building dance: Dance within the context of architectural design pedagogy. IJADE 30(1): 123-32.

Evered, Roger D. and Gerald I. Susman. 1978. An assessment of the scientific merits of action research. Administrative Science Quarterly 23(4): 582-603. https://doi.org/10.2307/2392581

Ferrance, Eileen. 2000. Action research. LAB.

Foster, Susan Leigh. 1986. Reading dancing: Bodies and subjects in contemporary American dance. Berkeley: University of California Press.

Gardner, Howard. 1993. Frames of the mind: The theory of multiple intelligences. New York: Basic Books.

Gavrilou, Evelyn. 2003. Inscribing structures of dance into architecture. In Proceedings: 4th International Space Syntax Symposium. London. http://www.spacesyntax.net/symposiaarchive/SSS4/fullpapers/32Gavriloupaper.pdf

Huang, Hilary Bradbury. 2010. What is good action research? Action Research 8(1): 93-109. https://journals.sagepub.com/doi/abs/10.1177/1476750310362435

Hurst, Anne. 2010. The lived experience of creative/therapeutic dance. Aukland: Auckland University of Technology. https://www.researchgate.net/publication/47388391

Janse van Rensburg, Ariane. 2015. Enabling transformation, a model for facilitating successful design outcomes in first year Bachelor of Architectural studies. Johannesburg: University of the Witwatersrand.

Laban, Rudolph. 1966. Choreutics. Macdonald \& Evans.

Lakoff, George. 1987. Women, fire, and dangerous things: What categories reveal about the mind. Chicago: The University of Chicago Press.

Lewis, Myrna. 2000. Inside the no: Five steps to decisions that last. 
Lopez y Royo, Alessandra. 2006. Dance - space - architecture. 2006. http://humanitieslab. stanford.edu/49/75

Mindell, Amy. 2001. Metaskills: The spiritual art of therapy. Lao Tse Press.

Moeller, Martin. 2006. Architecture \& dance: Intersections \& collaboration. An interview with Frances Bronet. National Building Museum: Telling the stories of architecture, engineering and design. July 2006. http://www.nbm.org/about-us/publications/blueprints/architecture-dance.html

Montello, Daniel R. 1995. How significant are cultural differences in spatial cognition? In Spatial information theory: A theoretical basis for GIS, ed. A. U. Frank and W Kuhn, 485-500. Berlin: Springer-Verlag.

Neumeier, M. 2013. Meta skills: Five talents for the robotic age. New Riders.

O’Brien, Rory. 1998. Web networks. www.web.ca/ robrien/papers/arfinal.html

Pickering, Lucy. 2009. Dancing my true dance: Reflections on learning to express myself through ecstatic dance in Hawai'i. Anthropology Matters 11(1): 1-12.

Reason, Peter and Hilary Bradbury. 2008. The Sage handbook of action research: Participative inquiry and practice. Second edition. Sage Publications.

Schlemmer, Oskar, Laszlo Moholy-Nagy and Farkas Molnár. 1979. The theater of the Bauhaus. Edited by Walter Gropius. Translated by Arthur S. Wensinger. London: Eyre Methuen Ltd.

Spurr, Sam. 2007. Chance encounters between body and buildings: New technologies in architecture and dance. In Association of Architecture Schools of Australasia. AASA \& UTS. https://opus.lib.uts.edu.au/handle/10453/7395

Van Schaik, Leon. 2008. Spatial intelligence: New futures for architecture. England: John Wiley \& Sons.

Vroman, Liselotte, Luiz Naveda, Marc Leman and Thierry Lagrange. 2012. Generating tacit knowledge through motion: A vision on the matter of space. Art, Design \& Communication in Higher Education 10(2): 255-269. https://doi.org/10.1386/adch.10.2.255_1 